Available online on 15.05.2020 at http://ujpr.org
Universal Journal of Pharmaceutical Research
An International Peer Reviewed Journal
Open access to Pharmaceutical research

\title{
PREVALENCE OF STAPHYLOCOCCUS AUREUS IN DENTAL INFECTIONS AND THE OCCURRENCE OF MRSA IN ISOLATES
}

Ameen Abdullah Yahya Al-Akwa ${ }^{1}{ }^{(D}$, Abdul Qader Mohammed Qasem Zabara ${ }^{1}{ }^{(D)}$, Hassan Abdulwahab Al-Shamahy ${ }^{2}$ (D) Mohammed A Al-labani ${ }^{1}{ }^{(D)}$, Khaled M Al-Ghaffari ${ }^{3}{ }^{(D}$, Ammar M Al-Mortada ${ }^{4}$, Ahmed M. Al-Haddad ${ }^{5}$ (i) , Amani Abdulhakeem Al-Sharani ${ }^{6}$ (D)

${ }^{I}$ Orthodontics, Pedodontics and Prevention Department Faculty of Dentistry, Sana'a University, Yemen.

${ }^{2}$ Departement of Basic Sciences, Faculty of Dentistry, Sana'a University, Republic of Yemen.

${ }^{3}$ Department of Conservative Dentistry and Oral Health, Sana'a University, Republic of Yemen.

${ }^{4}$ Department of Maxillo-Facial, Faculty of Dentistry, Sana' a University, Republic of Yemen.

${ }^{5}$ Department of Medical Laboratories, College of Medicine and Health Sciences, Hadhramout University, Al-Mukalla, Yemen. ${ }^{6}$ Oral Medicine and Periodontology Department, College of Dentistry, University of Sciences and Technology, Yemen.

\section{ABSTRACT}

Objectives: Staphylococcus aureus is an opportunist that causes systemic infections and dental infections in the human being body. This organism increases its resistance to many categories of antibiotics all day and turn out to be more resistant, and this led to a growing feeling of concern in this era. Given this fact, the aims of this study were to determine the frequency of $S$. aureus in oral infections and to determine the prevalence of MRSA strains and the sensitivity of isolated S. aureus to antibiotics, in patients who attended dental clinics in major public hospitals and private clinics in the city of Sana'a-Yemen.

Subjects and methods: The study was conducted for a year, early in December 2018 and ending in November 2019. The study included 296 patients, 153 male and 143 female, ages 5 to 65, with an average age of 36.2 years. Demographic and clinical data were collected in questionnaire, then pus or oral swabs were collected from patients, cultivated, isolated and identified by standard laboratory techniques. MRSA was ascertained by means of the method of disc diffusion to $1 \mu \mathrm{g}$ of oxicillin disc and $5 \mu \mathrm{g}$ of methacillin disc; an antimicrobial sensitivity test was carried out by disc diffusion method of selected antibiotics.The oral infections include dental abscesses, periodontal abscesses, gingivitis, periodentitis, dental caries, pulpitis and oral thrush.

Results: Of a total of 296 cultured pus and swabs, only 217 produced a positive culture (73.3\%). Gram-positive bacteria formed $67.4 \%$ of the total isolates where S. aureus was the predominant pathogen (43.1\%). The prevalence of MRSA was $23.5 \%$. There was a higher rate of antibiotic resistance tested in MRSA isolates compared to a lower rate of resistance in MSSA as well as $22.2 \%$ of MRSA isolates were vancomycin resistant, while only $11.4 \%$ of MSSA were vancomycin resistant.

Conclusion: It can be concluded, S. aureus was the most widespread isolate in dental infections, high rate of MRSA, the appearance of $S$. aureus isolates resistant to vancomycin and other broad choice of antibiotics have raised MRSA in oral infections into a multi-drug-resistant, making it more and more hazardous in oral infections. Consistent assessment of oral associated infections and observing the pattern of antibiotic sensitivity and strict drug policy for antibiotics are recommended.

Keywords: Antibiotic resistance, dental infection, MRSA, Staphylococcus aureus, Sana'a, Yemen.

Article Info: Received 2 March 2020; Revised 3 April; Accepted 5 May, Available online 15 May 2020

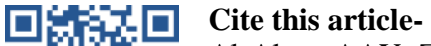

Al-Akwa AAY, Zabara AQMQ, Al-Shamahy HA, Al-labani MA, Al-Ghaffari KM, Al-Mortada AM, Al-Haddad AM, Al-Sharani AA. Prevalence of Staphylococcus aureus in dental infections and the occurrence of MRSA in isolates. Universal Journal of Pharmaceutical Research 2020; 5(2):23-27.

DOI: https://doi.org/10.22270/ujpr.v5i2.384

Address for Correspondence

Prof. Hassan A. Al-Shamahy, Faculty of Dentistry, Sana'a University, P.O. Box 775 Sana'a, Yemen, Tel: +967-1-239551,

E-mail: shmahe@yemen.net.ye

\section{INTRODUCTION}

The human oral cavity acts as a growth medium for pathogens as a result of its moisture, temperature, and nutritional content such as fats, carbohydrates, and protein ${ }^{1}$. There are numerous categories of dental infections that happen in the patient's oral cavity such as periodontal disease, tooth decay, dental ache, dental plaque, dental abscess, dental calculus, dentin hypersensitivity, hyperdontia, acid erosion, malocclusion, ulcerative gingivitis, dental fluorosis, tooth impaction, acute necrotizing, etc. $S$. aureus is a presumed pathogen for many oral diseases, such as oral mucositis, periodontitis, peri-implantitis, endodontic infections and even dental caries ${ }^{2-5}$. S. aureus is a Gram-positive, non-spore forming, non-motile, grape like clusters and the most important coagulase 
positive pathogen from staphylococci due to mixture of invasiveness, toxic mediated virulence and antibiotic resistance ${ }^{6}$. Some $S$. aureus strains have developed drug-resistant ${ }^{7}$. Methicillin-resistant $S$. aureus (MRSA) ${ }^{8}$ are the strains of $S$. aureus that have been resistant to beta-lactam antibiotics, which include penicillins, amoxicillin, ampicillin, methicillin, oxacillin, cephalosporins, etc ${ }^{9}$. The tendency of $S$. aureus to acquire antibiotic resistance led to a global dissemination of clone expressing various antimicrobial resistances. Many bacterial diseases occur in hospitals and in community due to MRSA strains and sometimes lead to death ${ }^{10-12}$. S. aureus infection, including MRSA strains, has long been common in Yemen $^{13}$. Because the arbitrary use of antibiotics is a typical practice, hospital environments are not clean enough and crowding of patients and health workers supports the spread of infectious germs including $S$. aureus $^{13}$. The potential presence of $S$. aureus is especially important in dental infections due to its increased resistance ${ }^{13,14}$. Therefore it is very logical to check the status of the microbial resistance against the commonly used antibiotics for the treatment of dental infections that occur by S. aureus. Considering this, the aims of this study were to determine the frequency of of $S$. aureus in oral infections and to identify the prevalence of MRSA strains and antibiotic sensitivity of isolated $S$. aureus, in patients attended the dental clinics at the main general hospitals and private clinics in Sana'a city-Yemen.

\section{PATIENTS, MATERIALS AND METHODS}

Patients: The study was carried out for a year, from December 2018 to November 2019. The study comprised 296 patients, 153 male and 143 female, ages 5 to 65 , with an average age of 36.2 years. The selected cases were defined as all patients who had a major complaint of various oral infections and entered the dental clinics previously mentioned. The technique of sampling in the study was case- finding. As for determining the size of the sample, it was relied on taking all patients who attended dental clinics during the study period and estimated one year in which the study materials were collected, which included clinical and demographic data, etc. Demographic and clinical data were collected in a questionnaire. After that pus or oral swabs were collected from patients, cultivated, isolated and identified using standard laboratory methods. The oral infections include dental abscesses, periodontal abscesses, gingivitis, periodentitis, dental caries, pulpitis and oral thrush.

Cases definition: All patients enrolled in this study, who had a major complaint of various oral infections and entered dental clinics in the city of Sana'a.

Data collection and processing: A questionnaire was filled out for each patient with the patient's personal and clinical data. This included age, gender, profession and relevant clinical information regarding bacterial and fungal oral infections. Upon initial hospitalization, cultures were obtained from the oral infection sites in order to isolate the causative agents of various bacteria and fungi.
Antimicrobial susceptibility test: Antibiotic resistance phenotypes (Methicillin/Oxacillin sensitivity test): All isolates of $S$. aureus were checked for the sensitivity to $1 \mu \mathrm{g}$ Oxacillin disc and $5 \mu \mathrm{g}$ Methicillin disc (Difco) by the disk diffusion method that instructed by NCCLS. The resistance breakpoints were $\geq 12 \mathrm{~mm}$ to $\leq 10 \mathrm{~mm}$ for $1 \mu \mathrm{g}$ Oxacillin and $\geq 14 \mathrm{~mm}$ to $\leq 10 \mathrm{~mm}$ for $5 \mu \mathrm{g}$ Methicillin. The capacity of extra antibiotic discs to inhibit MRSA or MSSA was estimated according to the instructions provided by NCCLS using commercially available discs that include: Augmenitin (AC $30 \mu \mathrm{g}$ ), tetracycline (T,30 $\mu \mathrm{g})$, erythromycin(E,15 $\mu \mathrm{g})$, ceftizoxime (CEF $20 \mu \mathrm{g}$ ), ciprofloxacin( $\mathrm{Ci} 5 \mu \mathrm{g})$, clindamycin(CC, $2 \mu \mathrm{g}$ ), clarithromycin $(\mathrm{Cl} 15 \mu \mathrm{g})$ and vancomycin $(\mathrm{V}, 30 \mu \mathrm{g})$. The zone of inhibition produced by $S$. aureus against each antibiotic was measured and interpreted as resistant and susceptible according to standards of Clinical Laboratory and Standards Institute ${ }^{15}$.

\section{RESULTS}

The positive culture rate was $73.3 \%$ and $26.7 \%$ of the specimens were negative (Table 1). A hundred and eighty $180(67.4 \%)$ were Gram positive bacteria, 71 (26.6\%) were Gram negative bacteria and 16 (6.0\%) were C.albicans. The most frequent microorganism isolated was $S$. aureus (115 isolates), followed by Bacteroides spp (71 isolates) and Strept. pyogens (38 isolates) with percentages of $43.1 \%, 26.6 \%$ and $14.2 \%$ respectively.

Table 1: Cultural results of the 296 patients with bacterial and fungal oral infections.

\begin{tabular}{lll}
\hline Results & No. & \% \\
\hline Positive cultures & 217 & 73.3 \\
Negative cultures & 79 & 26.7 \\
Total & 296 & 100 \\
\hline
\end{tabular}

Table 3 shows the susceptibility patterns of $S$. aureus isolates towards the different commonly used antibiotics. The resistant results for MRSA of antibiotics represented in number and percentages are shown in the following order: vancomycin (22.2\%), clindamycin (26\%), ciprofloxacin $(29.7 \%)$, ceftizoxime (40.7\%), calrithromycin (37\%), augmentin (55.6\%), tetracycline $(74 \%)$, and erythromycin $(23.3 \%)$.

Table 2: Distribution of the 217 positive culture isolates according to their group and genus.

\begin{tabular}{lcc}
\hline Isolates & No. & \% \\
\hline Gram positive bacteria & 180 & 67.4 \\
Staph. aureus & 115 & 43.1 \\
Strept. pyogenes & 38 & 14.2 \\
Staph. epidermidis & 16 & 6.0 \\
Strept. mutans & 11 & 4.1 \\
Gram negative bacteria & 71 & 26.6 \\
Bacteroides spp & 71 & 26.6 \\
Yeasts & 16 & 6.0 \\
Candida albicans & 16 & 6.0 \\
Total & 267 & 100.0 \\
\hline
\end{tabular}

The resistant results for MSSA of antibiotics represented in number and percentages are shown in the following order: vancomycin $(11.4 \%)$, clindamycin 
(30.3\%), ciprofloxacin (22.7\%), ceftizoxime (30.3\%), calrithromycin (26.3\%), augmentin (30.7\%), tetracycline $(72.7 \%)$, and erythromycin $(60.2 \%)$.

\section{DISCUSSION}

Dental patients typically take antibiotics primarily to treat postoperative and secondary infections. In the current study all 115 coagulase positive isolates of $S$. aureus were subjected to disc diffusion method to $5 \mu \mathrm{g}$ Methicillin disc and $1 \mu \mathrm{g}$ Oxacillin disc to determine MRSA; the test results discovered that $23.5 \%$ of isolated $S$. aureus were MRSA strain. The current rate of $23.5 \%$ of MRSA in all isolates of $S$. aureus is lower than the rate reported from Yemen in previous reports in which MRSA was isolated from $55 \%$ of health workers in Taiz, Yemen ${ }^{16}$, also it is very lower than that reported by al-Baidani and others ${ }^{17}$, among health care workers in Al Hodeida City, Yemen where the MRSA rate was $86 \%$. On the other hand, it was almost similar to that mentioned by Al-Safani et al. ${ }^{13}$ (19.3\%) among patients attending Military Hospital, Sana'a City; and Alyahawi, and others among patients of some private hospitals in Sana'a City $(17.6 \%),{ }^{18}$.

Table 3: The antibiotic sensitivity for 115 isolated MRSA and MSSA for tested antibiotics.

\begin{tabular}{|c|c|c|c|c|}
\hline \multirow[t]{2}{*}{ Antibiotics } & \multicolumn{2}{|c|}{$\begin{array}{c}\text { MRSA } \\
\mathbf{n}=27(\mathbf{2 3 . 5} \%)\end{array}$} & \multicolumn{2}{|c|}{$\begin{array}{c}\text { MSSA } \\
\mathrm{n}=\mathbf{8 8}(\mathbf{7 6 . 5} \%)\end{array}$} \\
\hline & Sensitive & Resistant & Sensitive & Resistant \\
\hline Augmentin & $12(44.4 \%)$ & $15(55.6 \%)$ & $61(69.3 \%)$ & $27(30.7 \%)$ \\
\hline Cefotaxime & $11(40.7 \%)$ & $16(59.3 \%)$ & $61(69.3 \%)$ & $27(30.3 \%)$ \\
\hline Ciprofloxacin & $19(70.3 \%)$ & $8(29.7 \%)$ & $68(77.3 \%)$ & $20(22.7 \%)$ \\
\hline Clarithromycin & $17(63 \%)$ & $10(37 \%)$ & $65(73.7 \%)$ & $23(26.3 \%)$ \\
\hline Clindamycin & $20(74 \%)$ & $7(26 \%)$ & $61(69.3 \%)$ & $27(30.3 \%)$ \\
\hline Erythromycin & $18(66.7 \%)$ & $9(23.3 \%)$ & $35(39.8 \%)$ & $53(60.2 \%)$ \\
\hline Tetracycline & $7(26 \%)$ & $20(74 \%)$ & $24(27.3 \%)$ & $64(72.7 \%)$ \\
\hline Vancomycin & $21(77.8 \%)$ & $6(22.2 \%)$ & $37(42 \%)$ & $51(58 \%)$ \\
\hline
\end{tabular}

HA-MRSA occurred at a higher rate than CA-MRSA in the world, but in Yemen the rates were similar for the HA-MRSA and CA-MRSA $(19.4 \%$ and $17 \%$, respectively), as mentioned by Al-Safani et al., ${ }^{13}$ and Alyahawi et al., ${ }^{18}$. This result can be explained by long hospitalization, random use of antibiotics, lack of awareness, and receiving antibiotics before coming to hospital, which are some of the potential predisposing factors for the appearance of MRSA in the hospital and community. Results of current study differs from that reported in the United States of America where a high incidence of MRSA occurred in a hospital-acquired $S$. aureus infection (HA-MRSA) (59\%), compared to a community-acquired infection of $S$. aureus $(17 \%)^{19}$. This difference can be explained by the CA-MRSA biology appearing to be different from the HA-MRSA and the MSSA, which may allow CA-MRSA to cause diseases other than those expected from MSSA ${ }^{20,21}$.

With the advent of HA-MRSA, it is likely that it not only replaced HA-MSSA, but also led to a comprehensive increase in Staph. aureus infection in healthcare settings ${ }^{22,23}$. In addition, almost all researchers say the same thing that inpatients and outpatients suffer from $S$. aureus/MRSA infection higher than $S$. aureus/MSSA due to the widespread prevalence of MRSA in a community environment and hospitals $^{23-25}$. When comparing MRSA rate with the MRSA rate in $S$. aureus dental infections, current study result $(23.5 \%)$ was almost lower than the $30 \%$ MRSA reported by Das Manisha et al., ${ }^{26}$. Also ,the prevalence of MRSA (23.5\%) was higher than the results of Ayepola et al., ${ }^{27}$ who reported $2.4 \%$, as well as Smith et al., ${ }^{28} 6 \%$ of MRSA positive isolates were reported in oral infection. Another study by Renvert et al., ${ }^{29}$ in Sweden, observed similar results associated with periodontitis patients.

According to Kurita et al., ${ }^{30}$ dental patients are not the only ones responsible for spreading MRSA bacteria, but a health professional may transfer this pathogen through their tools, so there are consistent guidelines for controlling MRSA as the CDC some standard precautions may be recommended which may help reduce the prevalence of MRSA among dental patients $^{31}$. The reason for conducting the current study was to know the prevalence of MRSA and the current antimicrobial profile of $S$. aureus in order to choose the appropriate empirical treatment for these oral infections. In current study, vancomycin resistance (VRSA) was $22.2 \%$ in isolated MRSA. This result differs from that reported in Asian countries where the vancomycin resistance rate was no more than $10 \%{ }^{32}$. The occurrence of VRSA in Asian countries has also been documented by Kaleem et al., ${ }^{33}$ in Pakistan to be $3.3 \%, 6 \%$ in India, by Sonavane and Mathur ${ }^{34}, 7.5 \%$ in Iran by Mehdinejad et al., ${ }^{35}$ and $9 \%$ in Jordan are from Al-Zoubi and others ${ }^{36}$. The current study results revealed that $73 \%$ dental S. aureus isolates were found resistant to tetercycline followed by $53.9 \%$ to erythromycin, $46.5 \%$ to augmanten, and $35.6 \%$ to Cefotaxime where low rates of resistant occurred for ciprofloxacin $(24.3 \%)$, Clarithromycin $(28.7 \%)$, and Clindamycin $\left(29.6 \%\right.$ ) (Table 3). Kim and Lee ${ }^{37}$ and Das Manisha et al., ${ }^{26}$ reported more sensitive strains of $S$. aureus isolated from the periodontal patients showed sensitivity $95 \%$ to ciprofloxacin (vs $75.7 \%$ ) and $90 \%$ to tetracycline (vs 31\%), 90\% to erythromycin (vs 46.1\%), and to $3^{\text {rd }}$ generation cephalosporins $95 \%$ (vs $62.4 \%$ ) that is comparatively higher than the current study. Similar antimicrobial susceptibility results were reported by previous authors ${ }^{8,38-40}$. The higher resistant rates in Yemen to commonly used antibiotics indicates indiscriminate or haphazard use that may have effect on treatment cost, poor prognosis as well as enhance the bacterial infection and growth virulent pathogens. 


\section{CONCLUSION}

The prevalence of $S$. aureus in dental patients is very high and showed resistance to commonly used antibiotics in addition to a high rate of MRSA. Despite these results, the sample size of this study was insufficient and the study period was too short to reveal the actual picture of MRSA involved in dental infection in Sana'a, Yemen. We recommend extensive studies to determine the prevalence of MRSA, genome analysis, identification of toxin gene and other antibiotic resistant gene. Teeth should be brushed regularly, maintain oral hygiene, and consulting with dental doctors to check up the teeth once in a month should be taken to maintain a distance from dental infections.

\section{AUTHOR'S CONTRIBUTION}

This research work is part of a research work under the supervision of Hassan Al-Shamahy. The field, clinical and laboratory works of the research was done by the corresponding author, the fifth author, the sixth author and the eighth author. The first, second, fourth, and seventh author supervised the work and edited the manuscript.

\section{ACKNOWLEDGEMENTS}

The authors thank the University of Sana'a for financial support.

\section{CONFLICT OF INTEREST}

No conflict of interest associated with this work.

\section{REFERENCES}

1. Mohapatra SB, Pattnaik M, Ray P. Microbial association of dental caries. Asian J Exp Biol Sci 2012; 3(2):360-367.

2. Gibson J, Wray D, Bagg J. Oral staphylococcal mucositis: A new clinical entity in orofacial granulomatosis and Crohn's disease. Oral Surgery, Oral Medicine, Oral Pathology, Oral Radiology, and Endodontology 2000; 89(2):171-176.

3. Heitz-Mayfield LJ, Lang NP. Comparative biology of chronic and aggressive periodontitis vs. peri implantitis. Periodontology 2010; 53(1):167-181. https://doi.org/10.1111/j.1600-0757.2010.00348.x

4. Poeschl PW, Crepaz V, Russmueller G, et al. Endodontic pathogens causing deep neck space infections: clinical impact of different sampling techniques and antibiotic susceptibility. J Endodontics 2011; 37(9):1201-1205. https://doi.org/10.1016/j.joen.2011.05.029

5. Passariello C, Puttini M, Iebba V, et al. Influence of oral conditions on colonization by highly toxigenic Staphylococcus aureus strains. Oral Diseases 2012;18(4):402-409.

https://doi.org/10.1111/j.1601-0825.2011.01889.x

6. Loir LY, Baron F, Gautier M. Staphylococcus aureus and food poisoning. Genetics and Molecular Research J 2003; 2(1):63-76. PMID:12917803

7. Faden A. Methicillin-resistant Staphylococcus aureus (MRSA) screening of hospital dental clinic surfaces. Saudi J Biol Sci 2019; 26(7):1795-1798. https://doi.org/10.1016/j.sjbs.2018.03.006

8. Rajaduraipandi K, Mani KR, Panneerselvam K, et al. Prevalence and antimicrobial susceptibility pattern of methicillin resistant Staphylococcus aureus: A multicentre study. Indian J Med Microbiol 2006; 24(1):34-38. https://doi.org/10.4103/0255-0857.19892
9. David MZ, Daum RS. Community-associated methicillin-resistant Staphylococcus aureus: epidemiology and clinical consequences of an emerging epidemic. Clin Microbiol Rev 2010; 23(3):616-687. https://doi.org/10.1128/CMR.00081-09

10. Bannerman T, Peacock S. Staphylococcus, Micrococcus, and other catalase positive cocci. In: Murray, P., Baron, E., Jorgensen, J., Landry, M., Pfaller, M. (Eds.), Manual of Clinical Microbiology $9^{\text {th }}$ ed. ASM Press, Washington, DC, 2007; 390-411.

11. Moussa IM, Al-Qahtani AA, Gassem MA, et al. Pulsedfield gel electrophoresis (PFGE) as an epidemiological marker for typing of methicillin-resistant Staphylococcus aureus recovered from King Saudi Arabia (KSA). African J Microbiol Res 2011; 5(12):1492-1499.

12. Peters PJ, Brooks JT, McAllister SK, et al. Methicillinresistant Staphylococcus aureus colonization of the groin and risk for clinical infection among HIVinfected adults. Emerging Infect Dis 2013; 19(4):623629. http://dx.doi.org/10.3201/eid1904.121353

13. Al-Safani AMA, Al-Shamahy HA, Al-Moyed KA. Prevalence, antimicrobial susceptibility pattern and risk factors of MRSA isolated from clinical specimens among military patients at 48 medical compound in Sana'a cityYemen. Universal J Pharm Res2018; 3(3): 40-44. https://doi.org/10.22270/ujpr.v3i3.165

14. Vellappally S, Divakar DD, Al Kheraif AA, et al. Occurrence of vancomycin-resistant Staphylococcus aureus in the oral cavity of patients with dental caries. Acta Microbiologica et Immunologica Hungarica 2017; 64(3):343-351. https://doi.org/10.1556/030.64.2017.033

15. Clinical and Laboratory Standards Institute [CLSI). Performance Standards for Antimicrobial Disc Susceptibility Tests. ( $11^{\text {th }}$ edn.), Approved standard M02-A11- Publication of Clinical and Laboratory Standards Institute [CLSI), 2012; USA, 32

16. Abdel Monem, MO. Nasal Carriage of Staphylococcus aureus among Healthcare Workers in Althawra Hospital, Taiz City, Republic of Yemen. Australian J Basic App Sci 2012; 6(7): 417-424.

17. Al-Baidani AR, El-Shouny WA, Shawa TM. Antibiotic susceptibility of MRSA in three hospitals at Hodeida city Yemen. Globle J Pharma 2011; 5(2):106-111.

18. Alyahawi A, Alkaf A, Alhomidi A. Prevalence of methicillin resistant Staphylococcus aureus (MRSA) and antimicrobial susceptibility patterns at a private hospital in Sana'a, Yemen. Universal J Pharm Res 2018; 3(3): 49. https://doi.org/10.22270/ujpr.v3i3.159

19. Fridkin SK, Hageman JC, Morrison M, et al. Methicillinresistant Staphylococcus aureus disease in three communities. N Engl J Med 2005; 352:1436-44. https://doi.org/10.1056/NEJMoa043252

20. Askarian M, Zeinazadeh A, Japoni A, et al. Prevalence of nasal carriage o Methicillin resistance Staphylococcus aureus and its antibiotic susceptibility pattern in healthcare workers at Namazi Hospital, Shiraz, Iran. Int J Infect Dis 2009; 13:e241-e247. https://doi.org/10.1016/j.ijid.2008.11.026

21. Mahalingam U, Thirunvukarasu T, Murugananthan K. Methicillin resistant Staphylococcus aureus among nurses in a tertiary care hospital in Sri Lanka. Ceylon Medical J 2014; S9:63-65. https://doi.org/10.4038/cmj.v59i2.7067

22. Elie-Turenne MC, et al. Prevalence and characteristics of Staphylococcus aureus colonization among healthcare professionals in an urban teaching hospital. Infection Control Hosp Epidemiol 2010; 31:S74-S80. https://doi.org/10.1086/652525

23. Radhakrishna M, D'Souza M, Kotigadde S, et al. Prevalence of methicillin resistant Staphylococcus aureus carriage amongst health care workers of critical care units in Kasturba Medical College Hospital, Mangalore, 
India. J Clin Diagnostic Research 2013; 7(12):26972700. https://doi.org/10.7860/JCDR/2013/5160.3735

24. Shibabaw A, Abebe T, Mihret A. Nasal carriage rate of methicillin-resistant Staphylococcus aureus among Dessie Referral hospital health care workers; Dessie Northeast, Ethiopia. Antimicrobial Resistance and Infection Control 2013; 2:25.

https://doi.org/10.1186/2047-2994-2-25

25. Iyer A, Kumosani T, Azhar E, Barbour E, Harakeh S. High incidence rate of methicillin-resistant Staphylococcus aureus among healthcare workers in Saudi Arabia. J Infect Dev Ctnes 2014; 8(3):372-378 https://doi.org/10.3855/jidc.3589

26. Das Manisha, Al Momen Sabuj Abdullah, Haque Zobayda Farzana et al. Characterization of Staphylococcus aureus isolated from human dental infection. Afr J Microbiol Res 2019; 13(14):273-278. https://doi.org/10.5897/AJMR2019.9076

27. Ayepola OO, Olasupo NA, Egwari LO, et al. Molecular characterization and antimicrobial susceptibility of Staphylococcus aureus isolates from clinical infection and asymptomatic carriers in Southwest Nigeria. Plos One 2015; 10(9):e0137531. https://doi.org/10.1371/journal.pone.0137531

28. Smith AJ, Robertson D, Tang MK, et al. S. aureus in the oral cavity: a three-year retrospective analysis of clinical laboratory data. British Dental J 2003; 195(12):701-703 https://doi.org/10.1038/sj.bdj.4810832

29. Renvert S, Lindahl C, Renvert H, Persson GR. Clinical and microbiological analysis of subjects treated with Brånemark or AstraTech implants: A 7-year follow-up study. Clin Oral Imp Res 2008; 19(4):342-347. https://doi.org/10.1111/j.1600-0501.2007.01476.x

30. Kurita H, Kurashina K, Honda T . Nosocomial transmission of methicillin-resistant Staphylococcus aureus via the surfaces of the dental operatory. British Dental J 2006; 201(5):297-300 https://doi.org/10.1038/sj.bdj.4813974

31. Harte JA. Standard and transmission-based precautions: an update for dentistry. The J American Dent Assoc 2010; 141(5):572-581. https://doi.org/10.14219/jada.archive.2010.0232

32. Mehmood A, Butt T, Usman M. A study on MRSA isolates to detect reduced susceptibility to vancomycin: A preliminary report. Infect Dis J 2007; 16:102-104.

33. Kaleem F, Usman J, Uddin Roz. Sensitivity pattern of methicillin resistant Staphylococcus aureus isolated from patients admitted in a tertiary care hospital of Pakistan. Iran J Microbiol 2010; 2(3): 143-146. PMID: 22347563

34. Sonavane A, Mathur M. Screening for vancomycin intermediate-resistant Staphylococcus aureus among clinical isolates of MRSA. Indian J Med Microbiol 2007; 25:79-80. https://doi.org/10.4103/0255-0857.31078

35. Mehdinejad M, Sheikh AF, Jolodar A. Study of methicillin resistance in Staphylococcus aureus and species of coagulase negative Staphylococci isolated from various clinical specimens. Pak J Med Sci 2008; 24:719-24.

36. Al-Zoubi, MS, Ibrahim Ali Al-Tayyar, Emad Hussein, et al. Antimicrobial susceptibility pattern of Staphylococcus aureus isolated from clinical specimens in Northern area of Jordan. Iran J Microbiol 2015; 7(5): 265-272. PMID: 26719783

37. Kim GY, Lee CH. Antimicrobial susceptibility and pathogenic genes of Staphylococcus aureus isolated from the oral cavity of patients with periodontitis. J Periodon Implant Sci 2015; 45(6):223-228. https://doi.org/10.5051/jpis.2015.45.6.223

38. Khan AH, Shamsuzzaman AKM, Paul SK, et al. Antimicrobial susceptibility and coagulase typing of MRSA strains at Mymensingh Medical College. Bangladesh J Med Microbiol 2007; 1(2):56-60.

39. Kim Y. Multiple antimicrobial resistance patterns of Staphylococcus aureus isolated from periodontitis patients in Seoul, Korea. Korean J Oral Maxillofacial Pathol 2012; 36:317-339. https://doi.org/10.5051/jpis.2015.45.6.223

40. Naeem M, Adil M, Naz SM, et al. Resistance and sensitivity pattern of Staphylococcus aureus; A study in lady reading hospital Peshawar. J Postgraduate Med Inst 2012; 27(1):42-47. 